\title{
EL HABEAS CORPUS EN AMÉRICA LATINA: ANTECEDENTES, DESARROLLO Y PERSPECTIVAS*
}

\author{
Domingo García Belaunde \\ Profesor de Derecho Constitucional de la Pontificia Universidad Católica del Perú. \\ Miembro fundador del Instituto lberoamericano de Derecho Constitucional. Miembro \\ fundador y Presidente de la Asociación Peruana de Derecho Constitucional.
}

\begin{abstract}
Sumario: 1. Introducción 2. Caracteres generales: aproximación 3. El problema de los nombres 4. Antigüedad y criterios 5. Etapas en su desarrollo: desde 1810 en adelante 6. El caso especial de México 7. Alcances del instituto 8. Configuración actual 9. Perspectivas.
\end{abstract}

\section{Introducción}

Como es de sobra conocido, el Habeas Corpus es una institución del derecho anglo-sajón que, nacida en Inglaterra en fecha incierta, pero en todo caso a mediados del siglo XIII, se extendió a sus colonias de ultramar (en especial, a las que luego serian los Estados Unidos), y de ahi a otros lugares más.

Asi, el Habeas Corpus ha nacido y se ha desarrollado sobre todo en su pais de origen, Inglaterra, o más en concreto, en el Reino Unido, y sólo más adelante en los Estados Unidos, asi como en otros paises de influencia inglesa.

Sin embargo, lo que no ha sido suficientemente estudiado es cómo llegó el Habeas Corpus a la América Latina, cómo se desarrolló y sobre todo, cuál es su fisonomía actual y sus perspectivas.

Pero podemos adelantar que, a nuestro criterio, uno es el Habeas Corpus nacido en la Inglaterra medieval y desarrollado luego en el contexto del common law, y muy otro es el que llegó a las tierras de América Latina, se adentró en su tradición jurídica de base romanista, y adquirió una fisonomía peculiar, acorde con las necesidades del medio. Esto nos lleva a hablar, por cierto, de una matriz del Habeas Corpus que es sajona con varios desarrollos independientes, o mejor aun, a sostener que al lado del Habeas Corpus sajón (fundamentalmente inglés y norteamericano), existe un Habeas Corpus latinoamericano, sobre el cual vamos a decir algo en nuestra exposición del día de hoy.

\footnotetext{
* El presente texto es la reconstrucción de mi intervención en el seminario organizado por el "Center for Constitutional Studies and Democratic Development" de la Universidad de Bologna, el día 2 de octubre de 2001, por gentil invitación de mi dilecto amigo el profesor Lucio Pegoraro. Por la naturaleza de la exposición, no entra en mayores detalles ni aporta aparato crítico. Pero al interesado en mayores referencias, remito a mi ensayo El Habeas Corpus latinoamericano publicado en el libro colectivo "Constitución y constitucionalismo, hoy", Fundación Manuel Garcia-Pelayo, Caracas, 2000. La versión inglesa tiene la siguiente ficha: Latin American Habeas Corpus en "Jahrbuch des Öffentlichen Rechts der Gegenwart", Band 49 , 2001. Publicado en AA.VV. "Influenze europee e statonitense sul costituzionalismo latino-ameriocano", Lib. Bonomo Editrice, Bologna 2002.
}

\section{Caracteres generales: aproximación}

Lo primero que cabe llamar la atención en el Habeas Corpus latinoamericano, es su relativa antigüedad, ya que si bien no es dable compararlo con el Habeas Corpus anglosajón, que nace a mediados del siglo XIII -si bien su desarrollo legislativo es muy posterior- tiene una vida que excede el siglo -aparece por vez primera en proyectos de 1810- y muy por delante de otros instrumentos que han aparecido o cuajado avanzado ya el siglo XIX, y quizá muy entrado el siglo XX.

El segundo aspecto que vale la pena considerar es su rápida recepción, y sobre todo, su continua expansión, que es característica, por asi decirlo, de un continente que durante todo el siglo XIX vivió en permanentes convulsiones políticas, y que en mayor o menor grado las sigue teniendo todavía. Y no sólo expansión a nivel legislativo, sino vigencia real y efectiva, y en cualquier caso, vivencia del instituto entre la población de la región.

Y el tercer punto, ya señalado, es que a diferencia del Habeas Corpus sajón, importante pero en cierto sentido restringido -como lo es aun el Habeas Corpus español- en la América Latina tiene características peculiares, llegando al extremo de que la mayoría de los paises latinoamericanos lo han introducido en sus constituciones, y hacen de dicho instituto un proceso ágil y garantista, cada vez más de un inequívoco contorno constitucional y con una cobertura muy amplia.

\section{El problema de los nombres}

Si bien desde un principio se conoció el instituto por su propio nombre, esto es, Habeas Corpus, en su difusión ha optado a veces un nombre distinto, pero que no deja lugar a dudas. Así, por ejemplo, en varios paises de Centroamérica se utiliza preferentemente el vocablo "exhibición personal", mientras que durante años, y fruto de la indefinición de la derogada Constitución de Venezuela de 1961, se le llamaba Habeas Corpus o Amparo. Y en Chile, se denomina como "recurso de protección", y se conoce como "amparo" al que está destinado a la tutela de la libertad personal. No obstante, la doctrina chilena entiende claramente lo que es un Habeas Corpus, y así lo señalan sus estudiosos.

Por tanto, si bien con algunas variantes, lo cierto es que la tendencia es que el nombre del instrumento procesal que se utiliza es el de Habeas Corpus. Y cuando se emplea otro nombre, hay acuerdo de que en el fondo nos estamos refiriendo a lo mismo. 


\section{Antigüedad y criterios}

Existe un debate, no muy extendido, sobre cuál sería la antigüedad del Habeas Corpus en la América Latina. Y esto por la sencilla razón de que no siempre existen criterios uniformes para fijar lo que es la institución, y también por la confusión terminológica o conceptual que existe entre los estudiosos.

Por tanto, a fin de precisar nuestro enfoque, creo que hay que distinguir dos aspectos: por un lado, la existencia de los derechos de la persona humana, en cuanto exigibles frente al poder, y por tanto, que el particular puede oponer a la autoridad. $Y$ entre ellos, la libertad individual. Esta es una conquista muy antigua y existe en todas las constituciones. La primera que se sanciona en la América Latina, la venezolana de 1811, muy influenciada por la de Estados Unidos de 1787 , asi como otras de la misma época (las locales que con anterioridad existian en lo que es hoy el territorio de Colombia), contienen declaraciones de derechos, que incluyen la libertad personal.

Sin embargo, la existencia de derechos proclamados o reconocidos por el Estado o en sus textos fundamentales, no significa que de por si sean respetados o que realmente sean vigentes. Este es el error en el que cayeron los revolucionarios franceses, y así se repitió en nuestros países. Esto es, la declaración de derechos no pasaba de ser eso y por si misma no garantizaba nada. Dicho en otras palabras: los derechos sólo se respetaban y protegían cuando existían adicionalmente instrumentos jurídicos que tenían ese objetivo y estaban diseñados para ello.

$Y$ por eso, cuando nos referimos al Habeas Corpus, estamos haciendo mención a un derecho instrumental, o sea, a un conjunto de procedimientos más o menos articulados, con los cuales se puede defender algo. Dicho en lenguaje moderno: el Habeas Corpus es un instrumento procesal, o un proceso destinado a la protección de otros derechos. Y sin importar cuál sea su nombre, es evidente que tiene un carácter adjetivo, ancilar en relación con otros fines, y que se realiza defendiendo a terceros ( $y$ asi lo fue siempre desde su aparición en la Inglaterra medieval).

Pero existen tendencias que identifican el derecho (libertad individual) con su instrumento de defensa, y creen que ambos son 10 mismo. Así, identificando el Habeas Corpus con la libertad individual, se sostiene que habría existido el Habeas Corpus en las constituciones de 1811(de Venezuela), y otras de la época o que vinieron después (por ejemplo, la chilena de 1833). Pero esta tesis es errónea. No se puede sostener válidamente que existe el Habeas Corpus si se carece de un procedimiento expeditivo para la libertad individual, configurado de manera expresa. La simple enumeración del derecho, no es suficiente. Aparte de los derechos, to que es necesario es la proclamación del instrumento protector, que en los casos mencionados, no se dio.

La creación de este instrumento protector puede hacerse por ley ordinaria o por norma constitucional. En el caso concreto del Habeas Corpus, lo que sucedió fue lo primero.

\section{Etapas en su desarrollo: desde 1810 en adelante}

Al parecer, la primera vez que se plantea seriamente la incorporación del Habeas Corpus a un ordenamiento positivo, fue en las
Cortes de Cádiz y en 1810.Como se sabe, estas Cortes, convocadas a raiz de la invasión napoleónica a España, y en la cual participaron no sólo españoles, sino también españoles de ultramar (como se conocía entonces a los habitantes de la América española y de las Filipinas) programaron y diseñaron un texto que sería aprobado en 1812, que tendría vasta influencia, tanto en la misma España, como en sus provincias de ultramar y, por cierto, en la misma Europa. Pues bien, en ella y en 1810, Manuel de Llano, diputado suplente por Guatemala, propuso incorporar el instituto del Habeas Corpus, siguiendo el modelo del que existía en Inglaterra, lo cual da cuenta del grado de información que en materia política y jurídica tenian las elites del Nuevo Mundo. El proyecto fue aprobado, según se sabe, para ser destinado, en medio del debate, al capítulo sobre el Poder Judicial, en donde finalmente se perdió en medio del tumulto de aquellos días. Pero la idea, sin lugar a dudas, quedó.

Otros más tarde, mencionaron el Habeas Corpus en sus proyectos de constitución, como es el caso de Ignacio López Rayón, en sus conocidos Elementos constitucionales de 1812 y que circuIaron en México, aun cuando no tuvieron vigencia alguna. $Y$ muchos más lo repitieron, como es el caso de Manuel Lorenzo de Vidaurre en 1827, y en relación con un proyecto constitucional que preparó para el Perú. Y también el proyecto de Eduardo Livingston de 1831 que confeccionó para la Luisiana, por influencia del ilustre Jeremy Bentham, y que fue traducido y recepcionado en Guatemala.

Pero es en el Imperio del Brasil en donde se consagrará, a nivel de derecho positivo, el Habeas Corpus y en 1830. Así consta en el Código Penal de ese año, que se reitera en el Código de Procedimientos Criminales que se sanciona en 1832.

$Y$ en 1837 es cuando el Habeas Corpus se incorpora en el derecho positivo de Guatemala, siguiendo al pie de la letra el Código de Livingston, antes citado. Posteriormente, en la Constitución de EI Salvador de 1841, se consagra por vez primera en América Latina el Habeas Corpus en el más alto nivel normativo.

A partir de esta fecha, el Habeas Corpus va a tener una influencia expansiva en el resto de los países del continente, influencia que perdura hasta ahora.

En este proceso queremos señalar algunas fechas adicionales, con carácter meramente referencial: i)Argentina incorpora el Habeas Corpus en 1863, ii) Honduras en 1865, iii) Chile en 1891, iv) Perú lo hace en 1897, v) Cuba en 1898, vi) Puerto Rico en 1898.

Entre algunos paises que han incorporado el Habeas Corpus en el siglo XX, señalemos los siguientes: i) Panamá en 1904, ii) Uruguay en 1918, iii) Ecuador en 1929, iv) Bolivia en 1931, v) Costa Rica en 1931, vi) Venezuela en 1947, vii) Colombia en 1964.

\section{El caso especial de México}

Lo importante del Habeas Corpus es que llegó a la América española por influencia de Inglaterra, y de ahí se expandió notablemente. Algo lentamente en el siglo XIX, pero con más fuerza en el siglo XX, aparece la presencia de los Estados Unidos en esta materia. Sin embargo, ellas no alcanzaron a México. Veamos por qué. 
México, como se sabe, era un Virreinato español que se asentaba en el territorio que actualmente ocupa, sin contar con los territorios perdidos en la guerra con los Estados Unidos, Guatemala y los países que hoy constituyen Centroamérica. De estos, algunos se perdieron solos (Texas) y otros se separaron, pero luego se reincorporaron, como es el caso del Estado de Yucatán.

Esto último explica por qué se adoptó el Amparo en la Constitución del Estado de Yucatán en 1841, sobre la base de un proyecto de 1840, y luego se extendió al resto de Estados mexicanos, plasmándose luego en la normativa federal.

Desde sus comienzos, México utilizó el Amparo como un instrumento procesal para la defensa de varios tópicos, entre ellos, el control de constitucionalidad, asi como la defensa de los derechos individuales, entre los cuales se encontraba la libertad individual. Esto es, el Amparo fue desde un principio un instrumento protector múltiple, que servia para defender varias cosas, entre ellas, la libertad individual. Dicho en otras palabras, el Habeas Corpus no existió, sino que tue subsumido dentro de un Amparo amplio y omnicomprensivo. $Y$ así se fue desarrollando desde 1847 hasta nuestros días, con numerosos cambios y aditamentos.

Esta posición especial de México de no aceptar el Habeas Corpus, sino una institución compleja que la comprendia dentro de ella, junto con otras más, es singular y no ha tenido seguimientos y es además fruto de su desarrollo histórico. Incluso en Centroamérica, tan receptiva de todo lo mexicano, esta postura no ha tenido predicamento.

Más bien, el desarrollo en Centroamérica ha sido distinto. $Y$ es que como estos pueblos tenian ya en su legislación y prácticas el instituto de Habeas Corpus con mucha anterioridad, aceptaron el Amparo como instrumento defensor de los derechos individuales, con excepción de la libertad individual, que reservaron a! Habeas Corpus. Esto es, en Centro América se dio desde muy temprano esta defensa bifronte de los derechos de la persona.

Y el mismo panorama se observa en la América Latina: existe el Habeas Corpus para la defensa de la libertad individual, y el resto de derechos son defendidos por el Amparo (o por otras instituciones similares, como son la Acción de Tutela, en Colombia; el Mandato de Seguridad, en Brasil, etc.).

\section{Alcances del instituto}

El Habeas Corpus nació primero en la jurisprudencia inglesa en el siglo XIII, y sólo más tarde alcanzó consagración legal, en especial con las leyes de 1640,1679 y 1816 . Y se ejercitaba a través de los writs, que perseguian defender la libertad individual, pero a través de diversas variantes. Por lo pronto, se admite que el writ of habeas corpus tenia en realidad siete modalidades, de las cuales la que está actualmente en uso y goza de mayor importancia, es el llamado habeas corpus ad subjudiciendum.

Y por tanto, estos son los que han pasado a la América Latina y son los más importantes. Sin embargo, tal traslado de instituciones no ha sido una labor mecánica, sino que ha tenido un evidente carácter creador, a tal extremo que el Habeas Corpus ha desarrollado perfiles que no se han visto en su país de origen.
Por tanto, hay que diferenciar el Habeas Corpus en sentido estricto, si bien no muy apegado al modelo inglés, que se da en ciertos países (como Argentina y Brasil) y el Habeas Corpus en sentido amplio, que se da sobre todo en el Perú, y se dio también en épocas pasadas en el Brasil.Y ahora en los países de Centroamérica, en donde el Habeas Corpus se ha utilizado también para enervar las torturas y para indagar por los desaparecidos.

Esto es, al ser recepcionado en los países de América Latina, ha mantenido el núcleo esencial que caracteriza a la institución inglesa, pero se le han hecho determinados ajustes, ampliaciones y perfeccionamientos, producto de las exigencias del medio en que le ha tocado desarrollarse.

\section{Configuración actual}

El Habeas Corpus fue en sus orígenes un procedimiento de orden penal y también civil, y casi como confundido con el resto de la legislación sajona existente. En la Constitución norteamericana de 1787 se le menciona, pero sólo de pasada, y para hacer referencia a cuando podía ser suspendido (ya que era una práctica comúnmente aceptada en las colonias y de continua observancia).

Pero lo que ha sucedido en la América Latina es peculiar. En primer lugar, y como no podia ser de otra manera, ha nacido en la ley, y más en concreto, en la ley penal, y luego se ha alojado en un código de la materia. Andando el tiempo, se ha mantenido así, pero ha tendido, ya en el siglo XX, a ubicarse en leyes especiales.

Y no sólo eso, sino que todos los países, en tiempos distintos pero convergentes, han elevado el Habeas Corpus al rango de instifuto constitucional. Es decir, se ha consagrado especialmente como una institución que nace en la Constitución y que desde ahí se desarrolla y se inserta en el mundo jurídico.

En las últimas décadas del siglo XX se han dado los pasos subsiguientes, como es replantear la institución a nivel doctrinario, $y$ luego a nivel de la dogmática.

Como consecuencia de ello, llegar a la conclusión, todavía no unánime pero de amplio consenso, de que el Habeas Corpus es un proceso constitucional, con amplio espectro, pero básicamente destinado a la protección de la libertad individual. En algunos países con una cobertura muy amplia, y en otros, con una más restringida.

Y el próximo paso será, sin lugar a dudas, la creación de leyes específicas sobre procesos constitucionales, que a la larga tenderán a consagrar la existencia de códigos procesales constitucionales (como es el caso de la provincia argentina de Tucumán).

Todo lo anterior nos lleva a la conclusión, ineludible por cierto, de que si bien con raíces sajonas, el Habeas Corpus ha tenido un desarrollo singular en la América Latina, que lo hace modélico y que constituye una de las características del constitucionalismo latinoamericano, que si bien heredero del constitucionalismo atlántico (Europa y los Estados Unidos), tiene sus propias peculiaridades.

Por cierto, el Habeas Corpus también existe en Portugal y en España, pero funciona bajo otros parámetros y no tiene la dimensión ni la importancia que se aprecia en la América Latina 


\section{Perspectivas}

El Habeas Corpus apareció, como ya se ha indicado, a mediados del siglo XIII, y de ahi se extendió a las colonias inglesas, como lo prueba en forma palpable el constitucionalismo norteamericano. $Y$ fue creado, precisamente, para combatir las detenciones arbitrarias hechas por las autoridades e incluso por los particulares, en épocas de autoritarismo y excesos notorios.

$Y$ asi fue evolucionando, con diversas modalidades y ha llegado a nuestro tiempo. Curiosamente, este desarrollo ha alcanzado muchas latitudes, pero no ha ingresado al corazón de la Europa continental (salvo los mencionados casos de Portugal y España). En algunos paises, sobre todo en los Estados Unidos y más acusadamente aun, en el Reino Unido, se aprecia el poco uso que se hace del Habeas Corpus o si se quiere, la restricción en su ámbito de acción. $Y$ esto no se debe a que la institución no sirva, sino que simplemente los paises evolucionan y los derechos humanos empiezan a respetarse más que antes. A primera vista, podria parecer que empieza a decaer, pero por desuetudo. $Y$ sobre todo en Inglaterra.
Pero estos hechos que podrían demostrar un cierto decaimiento de la institución, o mejor aun de su uso, no se dan en la América Latina. Es cierto que nuestro continente ha reiniciado, a partir de la década de los ochenta del siglo pasado, un retorno a la democracia, y esto es positivo. Pero ello no impide que los regimenes autoritarios vuelvan, ni tampoco que las democracias, pese a sus esfuerzos, no realicen excesos 0 cometan abusos. $O$ peor aun, que prosperen las democracias de fachada.

Descartar esto por ahora, es prácticamente imposible. Todavia faltan a nuestro continente las bases sólidas para que una democracia funcione de verdad y permanentemente.

$Y$ en este proceso de afianzamiento de las libertades, que puede durar décadas, las instituciones dedicadas a proteger la libertad individual, tienen un rol que cumplir en nuestros Estados. Por eso es que, con sus limitaciones, el Habeas Corpus tiene aun un papel protagónico en las agitadas democracias de América Latina. 